\title{
The discursive construction of the fathers' positioning within family participation frameworks
}

\author{
Francesco Arcidiacono • Clotilde Pontecorvo
}

Received: 24 June 2009 /Revised: 12 November 2009/Published online: 2 April 2010

(C) Instituto Superior de Psicologia Aplicada, Lisboa, Portugal and Springer Science+Business Media BV 2010

\begin{abstract}
The aim of this paper is to analyze how fathers position themselves within their everyday discursive practices at home. We consider the shift from a traditional father figure, defined and perceived as a provider, to an emerging collaborative one in order to explore the discursive acts of fathers' positioning through the observation of the everyday activities of eight middle-class Italian families. Adopting the positioning theory and the discursive approach as guiding analytical concepts, we discuss how fathers position themselves as representatives and as mediators of the family and of its everyday activities. We propose a qualitative analysis of discursive interactions in order to show how Italian fathers position themselves as active partners in different activities at home, ascribing meanings to what they do with the other family members and with the researchers.
\end{abstract}

Résumé Cette recherche vise à analyser comment les pères se positionnent dans leurs pratiques discursives quotidiennes à la maison. Nous considérons le changement de la figure traditionnelle du père, défini et perçu comme un provider, à une figure collaborative émergente, pour explorer les actes discursifs du positionnement des pères à travers l'observation des activités quotidiennes de huit familles italiennes de classe moyenne. Nous adoptons comme base de départ la théorie du positionnement et l'approche discursive. Nous discutons les façons par lesquelles les pères se positionnent en tant que médiateurs de la famille et de ses activités quotidiennes. Nous proposons une analyse qualitative des interactions discursives pour montrer que les pères se positionnent en tant que partenaires actifs au sein de différentes activités domestiques, donnant du sens aux actions accomplies avec les autres membres de la famille et avec les chercheurs.

Keywords Fatherhood $\cdot$ Positioning $\cdot$ Family interactions $\cdot$ Discursive practices

F. Arcidiacono $(\bowtie)$

Institute of Psychology and Education, University of Neuchâtel, Espace L. Agassiz, 1, 2000 Neuchâtel, Switzerland

e-mail: francesco.arcidiacono@unine.ch

C. Pontecorvo

Department of Developmental and Social Psychology, "Sapienza" University of Rome, Via dei Marsi, 78, 00185 Rome, Italy 
This paper focuses on everyday interactions of Italian families, in order to understand how fathers discursively position themselves within different participation frameworks. We consider as framework the real or conceptual structures intended to serve as a support or guide for the family members in order to give meanings to their actions. The aim of the study is to explore the mobilization of fathers' positioning during their activities at home in connection with the other family members and the researchers. In the first part of the paper, we will present the positioning theory and the discursive approach as guiding concepts of the study, as well as a short review of the literature on fatherhood in social sciences. Then, we will present and analyze qualitative data obtained through the ethnographic observations of eight middle-class Italian families. In particular, we will embrace and integrate both positioning and discursive perspectives, in order to explore how fathers discursively construct (in the course of different interactions at home) their positioning within family participation frameworks. Finally, we will discuss how participants jointly construct their positioning throughout the everyday interactions, suggesting some implications on current research into the ways family lives have changed over time, especially in men's work at home.

\section{The discursive approach and the notion of positioning}

The way in which people structure the ordinary talk and define themselves and others within everyday interactions provides insights on how those people socially function. In studying the discursive practices of the everyday life, the inquiry of talk-in-interaction focuses mainly on language use, and in particular on consequences of discursive actions within different participation frameworks. In this sense, family conversations are the analytical resources to study, for example, how different fathers' positions are made available and relevant during the interactions among family members. Within the discursive approach, there are no predetermined analytical categories: participants' accounts are always occasioned in the context of discourse and address the concerns of people engaged in the interaction. Accounts are thus not considered as definite facts about people's lives, but as alternative versions of their experiences of life, assuming the participants' own perspective (Edwards and Stokoe 2004). To illustrate a range of positions developed by participants during interactions, the discursive approach refers to the notion of “participants' categories" (Garfinkel 1967; Sacks 1992) in order to avoid making predictive assumptions regarding interactants' motivational, psychological, and sociological characteristics. In this sense, these factors can only be invoked only if the participants are "noticing, attending, or orienting to" them in the course of their interactions (Heritage 1995, p. 396).

In order to examine the mobilization of speakers' positions and its rhetorical effects, we also consider the positioning theory as a useful approach to illustrate the flexible and situated discursive moves of the participants. As suggested by Murakami (2007), positioning theory concerns the "attempts to articulate an alternative way of reading and understanding the dynamic of human relationships within a social constructivist paradigm" (pp. 437-438). The concept of positioning has been created as a metaphor to grasp how interactants are located within conversations: "positioning is the discursive process whereby selves are located in conversations as observably and subjectively coherent participants in jointly produced storylines" (Davies and Harré 1990 p. 48). Position is what is created in and through talk as participants take themselves up as people, and this term has been used for developing work in the analysis of fine-grained symbolically mediated interactions between people. Positions consist of a cluster of rights to perform certain meaningful acts in 
specific ways (Harré and Moghaddam 2003). As positions are relational, and people can and sometimes are offered the opportunity to acquiesce in such an assignment, contest, or subvert it, positioning theory focuses on understanding how psychological phenomena are produced in a discourse. The act of positioning refers to the assignment of functions to speakers in the discursive construction of a conversation: it is not a sign of fixed individual state of mind, but it is situated in discursive practices (Harré and van Langenhove 1999).

As positioning is a dynamic alternative to the more static concept of role, it can be understood as the discursive construction of storylines (inferred from situated talk, as opposed to personal stories examined in narratives studies) that make a person's action intelligible as a social act within which members of interactions have specific locations. Positioning can be understood as a way in which people dynamically produce and explain their own and others' everyday action. The concrete forms such positioning will take differ according to the situations in which they occur: "a subject position incorporates both a conceptual repertoire and a location for persons within the structure of rights for those that use that repertoire. Once having taken up a particular position as one's own, a person inevitably sees the world from the vantage point of that position and in terms of the particular images, metaphors, storylines and concepts, which are made relevant within the particular discursive practice in which they are positioned. At least a possibility of notional choice is inevitably involved because there are many and contradictory discursive practices that each person could engage in" (Davies and Harré 1990, p. 46). People could differ in their capacity to position themselves and others, in their intention to position and be positioned, and in their power to achieve positioning acts (Harré and van Langenhove 1998). As suggested by Davies and Harré (1999) “an individual emerges through processes of social interaction, not as a relatively fixed end product but as one who is constituted and reconstituted through the various discursive practices in which they participate" (p. 35).

From a constructionist point of view, selfhood is manifested in various discursive practices (Coulter 1981), and people discursively present themselves by ensuring that public performances conform to the requirements of the person-types that are recognized by the community. One's display of the characteristics of a person enters social space only in so far as it is recognized, responded to, and confirmed in the actions of others. As suggested by Shotter (1983), personhood is created primarily in the process of engaging in certain types of spoken discourse: by declarations and narrations people create discursive positions (Hollway 1984). In this sense, positioning theory is a starting point for reflecting upon the many different aspects of social life, because it is a helpful toolbox to understand the ways people act and ascribe meanings to what they do.

We think that the assumptions of the positioning theory (and the fact that different modes of positioning and insights into parity and power could be used by interactants) can be integrated within the discursive approach, in order to analyze the talk-in-interaction also in terms of turn taking, interruptions, hesitations, pauses, or the overall organization of the conversation. The attention to the structure, form, organization, and order of the interaction are relevant characteristics, because we are interested not only in structures and strategies but also in processes that activate participants' knowledge and opinions during a conversation.

\section{"Fathers" in the psychological research}

Over the past decades, the functions played by fathers in family lives have attracted considerable attention from developmental psychologists and social scientists. Recent social 
and cultural changes have prompted a re-definition of the father's image from a psychological, anthropological, and sociological point of view. Different studies (Le Camus 1987; Frascarolo et al. 1996; Frascarolo 2004) have pointed out that fathers play an active function within the family system, focussing on the paternal participation to childcare activities: Lamb (1997) has showed how "the closeness of the father-child relationship [...] is a crucial determinant of the father's impact on child development and adjustment" (p. 7). Other studies (Parke 1996; Zaouche-Gaudron 1997) have revealed the importance of the father's functions, comparing families where the father was present with families where he was absent, and analyzing the father's contributions to the family duties. Among studies that distinguish different types of fathers' conducts within families, Paquette et al. (2000) have analyzed the authoritarian, authoritative, and permissive images of fathers, and TamisLeMonda and Cabrera (2002) have investigated the quality and the effectiveness of fathers' involvements in families.

Recently, also within the Italian context, some psychological researches have emphasized a progressive shift from a profile of the detached and absent father embodying power and family authority, and confined to the role of economic provider, towards the idea of a "new father" (Drei and Carugati 2003; Arcidiacono et al. 2006). The new father began to play an active function within the family and to get involved in the development of children's personality and relational capacities, which had previously been regarded as an exclusively feminine domain. During the 1980s and 1990s, a great deal of empirical research has been made (Meyer-Kramer 1980; Badolato 1993) in order to lead to a 're-evaluation' of the paternal figure and to assess its importance for the psychological development of children, through quantitative and qualitative measures of the new fatherhood.

The new psychological interest to the fathers' positioning over the past decades is witnessed by the transition from the traditional fatherly image as provider to a more modern function as collaborator within the family. As we consider collaboration as a synchronous, coordinated effort by persons or groups working together (Roschelle and Teasley 1995; Arcidiacono 2007), in our case collaboration is the joint solving of a problem between the father and the other family members. We are thus confronted with an emergent father who engages in childcare alongside the mother, although this new image of fatherhood derives from a process that is still perhaps in the making (Scabini 1999; Ficeto 2000).

\section{Studies on fatherhood within family interactions}

The amount of time fathers spend within families with their children attracted a great deal of interest but turned out not to be effective in clarifying the complexity of father-child relationships. Since the 1970 s, time measurements have only shown wide variability, so that their poor reliability had already been assessed in the 1980s: time measurements are ineffective when they are unrelated to the content and the quality of interactions. For this reason, there is a recent interest to the father's involvement in family activities through the analysis of the relationships between fathers and new-born children (Dunn 2004). However, the images of fathers provided within this field of research appear similar to that of the 1950s: fathers assume less relevant functions compared to mothers, because traditionally they only appear to be involved when the need arises and with minor childrearing responsibilities (Lewis 1997). Studies within different cultures returned similar findings on this topic: a survey on parental couples in Germany has showed a growing fathers' tendency to withdraw from the interaction with children aged between 2 and 5 (Gauda 1983); Australian data have indicated that fathers 
equally share childcare with mothers only in $2 \%$ of families, and furthermore $60 \%$ of fathers declare that they never looked after their young children in the absence of the mother (Russell 1983). In a study of Japanese parents' sources of advice and information about childrearing, mothers received more advice and information from more sources compared with fathers (Shwalb et al. 1995). In Italy, sociological studies (Casanova 1997; Donati 1998) have considered the father as an intermediary between the family and the social system: fathers' responsibilities include the social development and the moral education of children, which will later help them integrate in society.

Most recent studies have tried to formulate theories around the concept of a new fatherhood (Maggioni 2000): the idea of an affective equality leads to a stabilization of identical expectations from both parents, and the new fatherhood implies the development of an "emotional" intelligence, traditionally considered as an exclusively feminine trait (Gottmann and Declaire 1999). Moreover, the assessment of different levels of fatherhood can influence and determine the representations of the fathers' positioning within families: for example, some studies focus on parental involvement (Lamb et al. 1987; Pleck 1997), in order to underline the fathers' positioning at the individual, familiar, extra-familiar, and cultural level. These studies have considered the amount of time fathers spend with their children and the nature of the activities they share together: in particular, authors have made a distinction between "engagement" (such as father-child interactions concerning food, sleep, play, and homework during which the father is at least available to interact), and "responsibility" (e.g., situations in which the father has a stronger mental charge of the childcare). Another interesting level of analysis concerns the consequences or the different effects of the fathers' presence at home to the child socialization, especially because of the increasing paternal involvement in the lives of their children between the 1980s and 1990s. In this sense, for example, the father's presence at home is considered as a model for the children's acquisition of gender roles, as well as an occasion to increase more generally the range of learning opportunities (Furstenberg 1998). However, such degree of involvement appears to be increasing also because of a parallel decrease in the amount of time working mothers are spending with their children. This tendency is also represented by popular media (such as fictions and other serials, as "S.O.S. Nanny", that is videotaped in real families with young children and weekly broadcasted by an Italian national TV channel) in which fathers are presented as active participants in family interactions. Even if there are few examples of studies concerning fathers who stay home alone with an infant or a toddler while the mother goes to work, this representation is progressively at stake. For example, within the Italian context, the major of Bologna has recently renounced his candidacy to another mandate at that position, because he has chosen to move himself from Bologna to Genoa, where his young partner lives and works with their 18 months toddler. In line with the representation of a new active father's image, this choice has been accepted as a proper position, although it has provoked a lively public discussion.

As suggested by Lupton and Barclay (1997), fatherhood "is commonly portrayed as a major opportunity for modern men to express their nurturing feelings in ways that their fathers supposedly did not, and to take an equal role in parenting with their female partners" (p. 1). However, we think that an aspect of ambivalence remains: the new fatherhood includes the need to defend themselves against what is perceived to be "feminine" characteristics and to feel less ambivalence about merging their identities with another individual. The ambivalent positioning of fathers contributes to reinforce the need to establish boundaries around the contemporary concept of fatherhood.

We need actually to look more specifically at the fathers' positions within their family participation frameworks, in order to point out the coarseness and the apparent presumed 
static nature of the typologies, personality variables, and modes of fatherhood. In spite of the amount of data collected by questionnaires and interviews, there are few evidences about the direct observation of the everyday interactions that define and shape the fathers' lives and for this reason, we choose to detect in detail how fathers differently position themselves within family participation frameworks. Even if the unique observation of families is not a sufficient parameter, we consider that through this method the reciprocity of the whole family relationships should be taken into account as a system of interdependent relationships, and the real meaning of fathers' positioning can be understood. Moreover, the participant observation can cause different reactions: Russell and Radojevic (1992) have showed how, in some cases, fathers seem to be more inclined to carry out performances for the observers and manifest less affection towards their children in family settings. This finding should prevent us from rushing to conclusions exclusively based on how fathers (and all family members in general) appear when observed. Thus, we consider that, when the researchers are present, family members no longer are acting just in the family unit only, but they act also within the larger context of the research. For this reason, we aim to analyze the discursive construction of fathers' positioning within the participation frameworks in which they act, through the detailed observation of everyday interactions at home.

In the following section of the paper, we will present the qualitative ethnographic data, in order to analyze some aspects of fathers' positioning within their discursive interactions at home with the researchers and the other family members.

\section{Methodology}

A research project on the everyday lives of families

The present study is part of an international project developed by three Centers on Everyday Lives of Families, based in the USA (UCLA, Los Angeles), in Italy ("Sapienza", University of Rome), and in Sweden (University of Linköping). The project is based on extensive ethnographic fieldwork in the domestic life of families, ${ }^{1}$ through the use of observational methodologies, in order to account the multidimensional character of the family life (Arcidiacono and Pontecorvo 2004).

This paper draws on data exclusively collected at the Italian Center on Everyday Lives of Families with the idea to undertake a qualitative analysis of the everyday lives of Italian middle class working families and to examine their everyday challenges. More specifically, in this study we propose a qualitative analysis of the discursive construction of fathers' positioning in the Italian families.

\section{Participant families}

The Italian Center on Everyday Lives of Families documented a week in the life of eight middle-class, dual-income families in Rome. ${ }^{2}$ Middle class is an unmarked reference group

\footnotetext{
${ }^{1}$ The research has been generously supported by the A. P. Sloan Foundation (New York, USA). We are grateful to our Swedish and American colleagues for discussing data and the methodological approach with us. We are also grateful to working families who participated in this study for opening their homes to us, letting us into their lives.

${ }^{2}$ The three centers share similar goals and criteria as far as the selection of participants is concerned.
} 
that is tacitly used as a model for research and policy decisions about family, welfare, and the participation of men and women in the workforce. Usually, middle class refers to the class or social stratum lying above the working class and below the upper class. Precisely because most families identify or hope to identify with the middle class, understanding tacit assumptions about middle class working families moved to the center of the research interest. We assume that the basis for the commonly expressed view to be middle class is therefore that many or most of families call ourselves middle class, and that the old badges of status of the working class are no anymore longer reliable.

To be eligible to participate in this study, families were required to be homeowners with a monthly mortgage or with a monthly rent and they had to have at least two children living at home, with at least one child aged between 8 and 11. Families were recruited through fliers in schools and personal acquaintances of the research team. During a preliminary meeting with the research team, both parents (and children over 8 years of age) have signed the participation consent forms and have received the instructions concerning timing and procedures of the study in their own houses.

\section{Aims and hypotheses}

The goal of the present study is to analyze how Italian fathers ${ }^{3}$ discursively construct their positioning during everyday family interactions, in terms of how positions are interactionally formed and oriented to the ongoing activities.

The hypotheses of the study are the following:

- there are different ways of fathers' positioning during family interactions at home; specifically, fathers position themselves as representatives of the families during the everyday activities performed in front of the researchers;

- there are different ways to discursively sustain and make explicit the fathers' positioning, such as to produce comments about a position during specific activities.

\section{Data collection, instruments, and criteria of analysis}

In order to achieve the research goal, we have employed the participant observation of the daily activities and interactions in the houses of the participant families. Each family has been video recorded over the course of a week for approximately a total of 20-25 h (per family). Three researchers have been engaged in 4 days (two weekdays and the weekend) of videotaping of family members inside their homes. The data have been then integrally transcribed (Jefferson 1985) $;^{4}$ all transcripts have been revised by two researchers (reaching a high level of consent) and then coded, using the topic of discourse as unit of analysis. We define the topic as the subject of a sequence of no less than three consecutive turns of at least two different speakers. See the following excerpt 1 as an illustrative example of the topic "sauce" during a parent-child cooking interaction.

\footnotetext{
${ }^{3}$ In this study, we use conventionally the terms "father" and "mother" to indicate the adult members of the families we observed. This choice is due to practical reasons: we recognize the fact that adults play different roles such as father/mother as parents, and husband/wife as a couple. However, we do not discuss here the distinctions about different possible cultural and social roles that participants can play during their everyday activities and interactions.

${ }^{4}$ See the Appendix 1 for the transcription symbols. For all participants, fictitious names replace real names in order to ensure anonymity in the presentation and in the analysis of the excerpts.
} 
Excerpt 1 "The sauce"

Cali family — Saturday morning video recording. Family members: father, mother, Carla (8 years old), Elisa (3 years old)

116. Mom: Look, come here! I put the onions in ((referring to the sauce she is preparing))

117. Carla: Delicious!

118. Mom: A little bit of oil

119. Carla: $\mathrm{mhm} \mathrm{mhm}$

120. Mom: As here I am making the sauce the one, with basil

121. Carla: Yummy!

122. Mom: Ok. Now you put it on the stove and stir it every now and then to avoid sticking. And this is a yummy sauce!

In order to analyze the data, we selected the conversational sequences in which the father was involved. For each sequence, we identified the topic of discourse. In particular, we considered the father's interventions not as isolated turns, but as a part of a sequence within the frame of the ongoing observed activities, because we consider possible to understand each turn only in connection with the previous and following one: "the organization of sequences is an organization of actions, actions accomplished through talk-in-interaction, which can provide to a spate of conduct coherence and order which is analytically distinct from the notion of topic" (Schegloff 1990, p. 53). For each sequence we have selected, we employed discursive analytic methods to closely examine the participants' interactions. In particular, the analysis draws upon conversational (Sacks et al. 1974) and discursive perspectives (Antaki 1994; Edwards et al. 1992), in order to identify on the one hand the structural elements of the conversation (such as words, sounds, and movements), and on the other the structures of meaning of the talk (overall topic, their organization in talk, local patterns of coherence in the sequence, implication, and assumptions). The analysis we propose in this paper is carried out on transcripts ${ }^{5}$ : firstly, we have identified the father's interventions within the selected sequences (see the criteria above), then we have examined the relevant (informative) passages by going back to the video data, in order to reach a high level of consent among researchers. Finally, we have built a collection of instances (Pontecorvo et al. 2001), similar in terms of criteria of the selection, in order to start the detailed analysis of the fathers' positioning during family interactions.

\footnotetext{
${ }_{5}$ Among different methods used within the research project on the everyday lives of families (semistructured interviews and questionnaires, mapping and photographing families' homes and belongings, tracking of family members' activities and uses of home-space, and participants' video recordings of the house), we propose in this paper data collected by videotaped observations. This choice is determined by practical reasons and by the idea to analyze specifically a part of our capta (in the sense that they are taken from a natural setting, and not built as artificial data), but always in relation to the data derived from the use of other methods we employed. In this way, the analysis of a specific sequence of a videotaped observation during the everyday interactions at home offers to us the possibility to identify some evidences about a certain aspect (e.g., the discursive father's positioning) that we could consider in the light of the more general image of family life we obtained by the use of other methods. For example, if a father, during a videotaped interaction, is referring to an object present in the domestic space, we can consider in our analysis the value of the object (e.g., as a symbolic resources), referring also to the evidence that comes from interviews, photographic collections, and tracking concerning the object. By going "forward and back" from a data source to another, we could have a more general understanding of the family interactions and representations.
} 


\section{The qualitative analysis of the discursive construction of the fathers' positioning}

In this section, we aim to present sequences of how fathers act their positioning within family interactions, through the analysis of different representative excerpts of conversations. Even if each family can be considered as a "case study", we are not interested here in doing comparisons among families: we have chosen to present different ways fathers discursively construct their positioning, in spite of considering singularly each father. For this reason, the excerpts below do not present situations coming from all the participant families, but only some sequences considered as representative cases. In this sense, we aim to highlight a spectrum of different positionings that fathers show in their family interactions at home. The excerpts will show how participants are continuously called to activate processes of positioning within families depending upon the interactions they have with the other participants. We have chosen to frame each excerpt in its context of production, naming each part as a "category" that accounts for certain types of discursive fathers' positioning. This option derives exclusively from the intention to make clear and easy the presentation of the excerpts, avoiding the use of pre-established categories. In fact, from an ethnomethodological point of view, courses of action that run off "routinely" must be regarded as "achievements arrived at out of a welter of possibilities for pre-emptive moves or claims, rather than a mechanical or automatic playing out of pre-scripted routines" (Schegloff 1986, p. 115). As a consequence, analysts have to remain sensitive to what interactants do, as well as to what they refrain from doing, to realize a given course of action (Maynard and Clayman 2003). The way in which we describe something is "reflexively" connected with our analysis. Considering the "membership categorization devices" (Sacks 1992), we recognize that it is through talking that members reflexively produce the social setting they inhabit in terms of objective features of everyday life. Thus, every effort is made to avoid general or ideal-typical characterizations of interactional procedures in favor of attending to specific instances as they unfold within, are shaped by, and in turn organize, concrete circumstances.

In the following sections, we will present a range of different fathers' positionings within different family subsystems: we will observe situations in which the father is called to act upon a particular function and he is inevitably "exposed" to his wife's gaze, especially if the action at stake is conventionally perceived as feminine. In some instances, the father can be downgraded to a "third son" position, subject to the mother's control and to her continuous monitoring. If, on the one hand, fathers tend to position themselves towards the filial subsystem within the family, they attempt on the other hand to be outside the family context, where their private individuality and uniqueness can emerge as more relevant.

The ambivalent positioning: the father as the mom's third son?

In the light of the abovementioned formulations, the different modalities of the fathers' positioning, and the shifts from a framework to another, can be understood in different ways: on the one hand, positionings can be considered as implicit acts when people become aware of the ambivalence; on the other hand, there are cases in which participants act explicitly, for example through childlike ironic/playful forms.

We present two sequences that concern different ambivalent fathers' positions within interactions at home. Excerpt 2 concerns the video recording of a weekday morning interaction between parents. The father is in the bedroom, in front of the wardrobe, looking for a shirt to wear, and the mother is in the kitchen, preparing breakfast for the 
children that are with her in the same room. At the beginning of the excerpt, there is a conversation going on between the parents who communicate from different rooms. Then the mother comes to the bedroom and goes back to the kitchen just before the end of selected sequence.

Excerpt 2 "Where is my shirt, Gaia?"

Ripe family-Thursday morning video recording. Family members: father, mother, Leonardo (13 years old), Andrea (9 years old)

1. Dad: Gaia ((la madre)) ma io una volta non avevo una camicia grigia? Ve la siete venduta?

2. Mom: può darsi che sia bagnata.

3. Dad: Oddio

4. Mom: Ti serve un'alternativa?

5. Dad: Mi serve una cosa da mettere sotto il vestito grigio

6. Mom: Arrivo

7. Dad: Mi metto la camicia bianca? ((davanti all'armadio, mentre la madre arriva))

8. Mom: Come mai il vestito grigio oggi?

9. Dad: Così

10. Mom: Ti senti serio?

11. Dad: Mi sento serio? Perché devo essere serio?

12. Mom: Scusa, però la camicia grigia sul vestito grigio! No!

13. Dad: O bianca?

14. Mom: Sembra che vai a un funerale, no? Ti devi mettere una cosa...un pò più allegrotta, scusa eh?

15. (6.0)

16. Mom: Al limite ti metti una camicia rosa

17. Dad: è quella coi gemelli?

18. Mom: No!

19. Dad: No.

20. Mom: Oppure celeste pallido pallido se proprio vuoi stare sul serio

21. Dad: Aspetta questa, [è quella viola ((mostrando una camicia))

22. Mom:

[No, questa non è celeste

23. Dad: è viola

24. Mom: è viola. Va bene, anche viola volendo

25. Dad: E, allora è meglio viola $(2.0)$ che rosa

26. Mom: Eh, insomma no grigia! ((andando via))

27. Dad: Va bene, va bene

28. Mom: Okay
Gaia ((the mother)) but didn't I use to have a grey shirt? Did you sell it?

It might be wet.

Oh my god

Do you need another one?

I need something to put under my grey suit

I'm coming

May I wear a white shirt? ((in front of the wardrobe, while the mother is coming))

How come a grey suit today?

Cause

Do you feel like being serious?

Do I feel serious? Why should I?

Excuse me, but a grey shirt under a grey suit! Way!

A white one?

It looks like you are going to a funeral, aren't you? You should put on something...brighter, sorry huh?

(6.0)

At least wear a pink one

The one with cuff-links on it?

No!

No.

Or at least the light light blue one if it is so important to be serious

Wait a minute this, [is the purple one ((showing a shirt))

It is purple

It is purple. Oh well, purple could do

So, then it is better the purple (2.0) than the pink one

Well, at least not grey! ((leaving))

Ok, ok

Okay 
In this excerpt, the father turns to his wife in order to find a shirt: he starts by an ironic claim about his shirt (turn 1, "Gaia but didn't I use to have a grey shirt? Did you sell it?"), asking help to the mother. In his ironic claim, the father makes explicit that, within this frame of interaction, he finds himself on one side, while the "other" family members are on the opposite side. The father uses irony as a speech act that distances the point of view of the speaker in relationships to the other interlocutors: in fact he is also using the second person plural that has the same aim. Different studies (Jorgensen 1996; Hutchby 2001; Eisterhold et al. 2006) have highlighted how the irony requires a complex inferential chain in order to grasp the communicative intention of the speaker. As a speech act, irony involves mental representations of different degrees of complexity and, as underlined by Brown and Levinson (1987) it may be used also for face-saving.

After a first justification (turn 2, "it might be wet"), the mother asks whether an alternative is needed. Her turn 6, "I'm coming", is at the same time the signal that confirms the need of her help and the claim of a possible solution for the father. During this construction of the frame by the participants, the father shifts from a position of total dependence on the mother (turn 5, "I need something to put under my grey suit") to a timid proposal or attempt of a choice (turn 7, “may I wear a white shirt?"). However, the mother's answer is considering the claim of the father in turn 5, in order to question his choice (turn 8, "how come a grey suit today?") and to assign a psychological state of mind to him (turn 10, "do you feel like being serious?"). This progressive construction of the dependence of the father on the mother in order to choose a shirt is confirmed by the following interventions of Gaia: when the father rejects the assumption made by the mother (turn 11, "do I feel serious? why should I?"), she immediately re-addresses the conversation on the topic of the shirt choice, in order to contrast the previous suggestion by the father (turn 12, "excuse me, but a grey shirt under a grey suit! way!"), and also the second one (turn 13 "a white one?") that is a father's re-formulation of the claim at the turn 7. The following interventions of Gaia (turn 14, "it looks like you are going to a funeral, aren't you? you should put on something brighter, sorry huh?", and turn 16 "at least wear a pink one") sound like both an explanation and a new solution (as well as in turns 20 and 24) about the shirt choice. At this time, the position of the father remains in some way dependent: even in turn 15, he does not take up the turn's conversation (producing a pause of six seconds), giving to the mother the possibility to continue her interventions; only at the end of the sequence, the father tries to indicate his preference (turn 25, "so, then it is better the purple than the pink one"). As this father seems to depend on the mother, his positioning is somehow related to the ambivalent image of fatherhood that, on one hand, is trying to defend himself against a "feminine-considered" feature (i.e., being able to combine well dress colors), and, on the other hand, feels the need to assume a personal choice to express his identity. However, the reaction of the mother (turn 26, "well, at least not grey!") sounds like a final statement, according to the claim of turn 12, and confirming that the best choice is not the gray shirt but something else. At the same time, she leaves the bedroom and the father accepts the end of the sequence (turn 27, "ok, $o k$ "), as the signal that no further discussions or debates are possible.

In the excerpt Gaia uses the situation to gain control over the father's choices: after the father's introduction of the topic asking the mother for his gray shirt, she answers and comments the father's choices negatively, and in so doing the father can only choose among the alternatives offered by the mother. In this sense, she contributes to position the father in a condition of dependence by taking advantage of the shirt's choice. Even if there is an ambivalent positioning of the father, the final joint decision of both partners is a sign that the new Italian fatherhood can be characterized by a 
tendency to be collaborative and to negotiate the moves during the everyday interactions.

In another family, we observe an interaction among parents and children in which the father tries to "join" children who are about to go to play. In this case, he positions himself within the daughters' subsystem, also through a particular language use. Excerpt 3 concerns a weekday video-recording at the end of the dinner. Family members are discussing on what they have to do: as the mother is supposed to wash dishes, the father proposes to the children to go and play together in another room.

Excerpt 3 "Can we play, mom?"

Pico family-Wednesday evening video recording. Family members: father, mother, Daniela (12 years old), Serena (10 years old)

340. Dad: Vabbè mamma che facciamo?

341. Serena: Che fa::

342. Mom: Che mi aspetta:: oddio::

343. Dad: I piatti dove c'è stata la frittata te li lavi tu perché dopo-

344. Mom: cioè praticamente tutti

345. Dad: ne abbiamo salvati tre. vabbè dai aiutiamo mamma un attimo

346. Mom: No $=$ no

347. Dad: No? Andiamo a giocare:: ci fai giocare mamma?

348. Mom: sì

349. Dad: Brava:::

350. Mom: Tanto lo fate tutte le sere, non è che::

351. Dad: Hai sentito Tomas? ((il cane del vicino abbaia)) anche Tomas ha detto vai vai:: hai sentito Tomas: vai vai, Tomas ha acconsentito (4.0) andiamo in cameretta ((padre e figlie escono dalla cucina e vanno in cameretta))

\section{Okay mom what do we do?}

What does she do::

What awaits me:: oh my god::

The omelette dishes you have to wash on your own, because later on-

Practically all of them

We saved only three plates. okay let's help mom for a while

No $=$ no

No? Shall we go and play:: are you letting us play mom?

Yes

Well-done::

You do it every evening anyway, it is not that::

Have you heard Tomas? ((the neighbour's dog is barking)) Tomas too said go go:: have you heard Tomas: go go, Tomas agrees (4.0) let's go to the little room ((the father and the children leave the kitchen and go to the children's bedroom))

The family has just finished eating and the father asks what they have to do, and playfully and ironically aligns himself with the children to "face" the mother. In turn 340 ("okay mom what do we do?"), he uses the first person plural in order to signal a position that is built on two sides: the mother versus the others (father and children together). This ongoing alliance is confirmed by the intervention of Serena (turn 341, "what does she do"), that enforces the positions and stresses in some way the "mother's matter". Father also in turn 345 ("okay let's help mom for a while"), maintains this frame using the plural to propose to help the mother, even if just for a while. Even if the mother states not to need their help (turn 346, "no=no"), the father makes explicit the intention to go and play with the children, asking the mother's consent (turn 347, "no? shall we go and play, are you letting us play mom?"). In this way, he guarantees his position on the children's side versus the mother. Also the mother aligns with the structure of alliance within this specific framework, through a recontextualization (Ochs 1990) of the situation (turn 350, "you do it 
every evening"). In this excerpt, the father's positioning is constructed during a situation of transition, such as the change of activities after the dinner. The father positions himself as the third son, because he shows closeness to the children needs. In so doing, the father joins the daughters not only in the sense that he enters into an alliance versus the mother, but also by the use of epistemic and affective stances (turns 340 and 347): he sustains the mother's position as a person that knows better how to wash dishes, and affectively as the person that allows both the daughters and the father to go to play together. Ochs (1992) emphasizes the importance to look at the whole situation of communication between adults and children in order to recognize the value of the indexical properties of speech through which particular stances and acts constitute a context. For example, linguistic forms may help to constitute local conceptions of participants' positions at the time a particular utterance is produced or is perceived. Excerpt 3 shows how the father, taking a position close to the children, refers to the wife as the mom (turn 340, "okay mom" and turn 347, "are you letting us play mom?") and uses claims typically employed in relation to and by children (turn 349, "well-done"). Finally, the father personifies the neighbor's dog (turn 351, "Tomas too said go go...Tomas agrees"), in order to reinforce his position and to legitimate the choice to leave the kitchen with the daughters.

Excerpts 2 and 3 have showed fathers that position themselves as mom's third son, even if in different ways: they demonstrate to consider the frameworks of the interaction in order to accept the control of the wife in situations of personal responsibility (such as dressing choices), as well as of household activities (such as washing dishes).

\section{The father as translator of his own activities and of the family}

Fathers are not just actors of the observed family interactions, but they can assume a more active role within the framework of the research. They take over the role of observing participants who, while trying to share the ethnographer's research horizon, become informants of their own contexts. This image of "translator" of the family world belongs to the traditional parental position towards children, but it is innovative when carried out towards the researcher. The everyday activities are carried out by some fathers in this informative participative style through the game of being both inside the activities (as actors), and outside (as an external voice that explains and translates verbally all that is being done). We also observe fathers who set aside for themselves a self-representative place when they inform about themselves, and their own point of view in the interactions with the researchers. Fathers shift back and forth between their interchangeable positions as native and as participant observers, probably because they aim to share the ethnographers' research horizons, through a distance from the family's world and conveying it to the outside. As showed by Goffman (1959), people improve and protect their status in front of others: in this perspective, participants are trying, within different settings, to position themselves with regards to an audience. While aware of being the object of a research project, participants could engage themselves in narratives that accompany and make their activities and thoughts explicit in front of researchers. It is the case in which fathers become translators (for the benefit of people that are not members of the family) of every portion of the world they presume will not be immediately understood by the researcher. In particular, in some cases, fathers want to conquer the possibility to verbally explain to the researcher the family's conducts, for example introducing the actions they are about to perform.

In the following excerpt, a father is organizing boxes under the desk in the bedroom: after a question of the researcher, who is personally interested in the boxes topic, the father starts to talk with the researcher about the activity he is doing. The other family members are meanwhile engaged in other activities in different rooms. 
Excerpt 4 "Yes, I have decided"

Cali Family - Wednesday evening video recording. Family members: father, mother, Carla (8 years old), Elisa (3 years old)

77. Dad: >questa ((mostrando la scatola)) piace a me e me la tengo io < loro ci fanno gli scarabocchi ((mima lo scarabocchio sul foglio come se fosse prodotto dalle bambine)) fanno il monitor (2.0) è già successo ( ) questa me la tengo però questa la devo buttare ((guardando un'altra scatola))

78. Researcher: buttare l'altra ${ }^{\circ}$ che non ha nulla di speciale $^{\circ}$

79. Dad: 'l'altra non c'ha niente di $\operatorname{speciale}^{\circ}(5.0)$ si. ho deciso. (5.0) le porto tutte e tre in canti::na (.) in realtà qui so esattamente cosa farci ((mettendo la mano su una scatola)) qui no. ((ne prende un'altra)) però sono troppo belle e le porterò in cantina. ((prende un'altra scatola da sotto la scrivania)) in realtà qui ho un sacco di carta che riciclo, che non posso buttare ((prende delle cose da buttare e va in cucina)) (30.0)

After few minutes

118. Dad: ((ordina sotto e sopra la scrivania)) adesso viene una cosa complica: :ta (.) dove la metto sta roba qui? ((continua a sistemare cose)) (28.0) normalmente queste cose sono demanda::te:: al (4.0) al fine settimana (.) quando sono più::: libero

119. Researcher: quando c'è più tranquillità?

120. Dad: si un po' più di tranquillità. però accade:: che qualche volta, si riesce a ritagliare durante la settimana, una mezz'o::ra (.) un'o::ra (.) appunto come questa, quando le bambine fanno la doccia:: o guardano un carto::ne, quando si sa cosa fare per cena, pronta magari, e allo:::ra e allo:::ra l'imp- io li impiego in questa maniera. alle volte mi si può trovare qui, $>$ se il posto per ese::mpio < prima che finissi di progettare e realizzare questo tavolo, stavo qui le mezz'ora intere apparentemente a non far niente, in realtà a pensa:::re > come risolvere questi problemi<
$>$ I like this one ((he shows a box)) and I'm going to keep it $<$ they scribble all over it (he mimes $a$ scribble on the piece of paper as it is done by the children)) they do the computer screen (2.0) it has already happened ( ) this one I keep but this one I have to throw away ((looking at another box))

To throw away the other one ${ }^{\circ}$ that has nothing special ${ }^{\circ}$

${ }^{\circ}$ The other one has nothing special ${ }^{\circ}(5.0)$ yes. I have decided. (5.0) I'm taking all three of them to the base::ment (.) actually here I know exactly what to do ((putting his hand on a box)) here I don't know. ((he takes another one)) but they are too nice and I'll bring them to the basement. ((he takes another box from under the desk)) actually here I have a lot of paper that I am recycling, that I can't throw away ((he takes some things to throw away and goes into the kitchen)) (30.0)

((he organizes things on top of and under the desk)) now a complica::ted thing (.) where do I put this stuff here? ((he continues to arrange things)) (28.0) normally these things are postpo::ned::: to (4.0) the week-end (.) when I'm more:: free

When it is more quiet?

Yes a bit quieter. but it happens:: that sometimes, during the week one manages to set aside, a half ho:: ur (.) an ho::ur (.) just like this, when girls take a shower:: or watch a carto::on, when you know what to cook for dinner, something ready maybe, and the::: $\mathrm{n}$ and the:::n I us- I use them this way. sometimes I can be found here, >if the place for exa::mple < before I finished to plan and make this table, I was here for an entire half hour apparently doing nothing, but actually thinki:::ng > how to solve these problems $<$

While translating the activity, fathers discursively position themselves explaining actions they are doing. In excerpt 4, the father is choosing which boxes he wants to keep (turn 77, " $I$ like this one and I'm going to keep it"), which ones he will take to the basement and which ones are to be thrown away (turn 77, "this one I have to throw away"). In organizing this family household activity, the father positions himself within a frame that involves both the narrator and the researcher. When the criteria of selection revealed by the father are reformulated by the researcher (turn 78, "you'll throw away the other one that has nothing special"), the construction of the narrative becomes collaborative, and the father translates to 
the researcher the actions that he is about to perform. Along the sequence, the father takes the position of a planning person who solves family's problems, even when they are not perceived as such by other family members. During the actions and the narratives, he is translating to the researcher the context in which he is performing something: in turn 118, the father remarks on the time of the action he is performing and points out the moment in which it is usually carried out ("normally these things are postponed to the weekend when I'm more free").

In this excerpt, space too has an important place in "translating" the context, because actions are generated and performed towards the objects that are present in the space (Giorgi et al. 2007). It is from boxes contained in the room that the action of putting them into place is generated and the father translates the action for the researcher's benefit: also in turn 120, the father explains his action starting from an object that is on the table. In this sense, objects around his setting become relevant for the action not only at that particular moment, but in the past too: objects encompass a personal history of actions that is brought to life through the native's narrative. Space and objects are turned into living entities through the native's translation; they are endowed with a past, a personal history, as well as past or future actions that are performed through them; and this process is made visible through the attribution of relevance to each component present in the context (Goodwin 1981). In the sequence, objects take a fundamental role not only in the narrative of the father's actions, but also in recounting the family worlds in the eyes of the father; in particular, in turn 120 ("I was here for an entire half hour apparently doing nothing, but actually thinking how to solve these problems") the father underlines the relevance of the space in which he is talking with the researcher, through the description of the time he spent in planning the family space organization.

The father as mediator

In the course of everyday routines, fathers often support or oppose the partner and/or other family members, positioning themselves as mediators within family interactive frameworks, as in the case of the father presented in the following excerpt.

Family members are all in the kitchen, around the table, having their breakfast. We focus on the conversation between the mother and the father (about the behavior of the babysitter who was with the children the day before, when children went to a movie), even if there is a parallel conversation between the parents and Elena, who is preparing her back pack for the school day.

\section{Excerpt 5 "The money"}

Giti family_-Tuesday morning video recording. Family members: father, mother, Elena ( 8 years old), Alice (1.5 years old)

8. Mom: Senti, ieri Katia ((la babysitter)) dice "ti devo dare dieci euro" ((rientrando dal cinema))

\section{Dad: [Dieci euro?}

10. Elena: [Ma non avevi scritto- ma non avevi scritto la cosa ((al padre))

11. Dad: Di che?

12. Elena: ((cantilenante)) portare la ( ) portare colla,

13. Mom: Ma non c'avevi la colla?
Listen, yesterday Katia ((the babysitter)) says "I have to give you ten euros" ((coming back from the movie theater))

[Ten euros?

[But hadn't you written- hadn't you written down the thing ((addressing to the father))

About what?

((sing a song voice)) bring in ( ) bring in glue,

Didn't you have the glue? 
14. Dad: Oh! ((imitando la voce di Elena)) controllare [l'astuccio,

15. Elena: [l'astuccio,

16. Mom: Ma che cosa ti mancava?

17. Elena: NO::

18. Dad: No, c'aveva tutto solo che non l'aveva scritto. Vabbè.

19. Mom: Niente, mi voleva dare dieci euro. ((riferendosi alla baysitter)) io gli ho detto " $\mathrm{mi}$ devi dare un po' di più". era così imbarazzante, non so se l'ha fatto apposta

20. Dad: No:

21. Mom: allora è scema.

22. Dad: No: non c'ha pensato

23. Mom: Come non c'ha pensato?

24. Dad: No ha fatto, sai, i conti come quando resta di solito::,

25. Mom: Anche l'altra volta con me, però era così imbarazzante

26. Dad: Ma poi si è resa conto comunque

27. Mom: Si: però era stato imbarazzante comunque

28. Dad: Sennò la prossima volta lo giro direttamente un film. lo produ:co. tra pagare $i$ biglietti, la babysitter, ((cantilenando))
Oh! ((imitating Elena's sing a song voice)) control the pencil [purse,

[purse,

But what were you missing?

NO::

No, she had everything only she hadn't written it down. Oh well.

No, she wanted to give me ten euros. ((referring to the babysitter)) I told her "you have to give me a little bit more". it was so embarrassing, I don't know whether she did it on purpose

No:

She is dumb then.

No: she didn't think about it

What didn't she think about?

No she counted, you know, as if she'd done her usual::

Last time she did it with me too, but it was so embarrassing

Well but then she realized in any case

Yes: but it was embarrassing nonetheless

Otherwise next time I'd better shoot the movie myself. produ:ce it. because buying tickets, paying the babysitter, ((sing a song voice))

The conversation between parents is constructed on the emotional overtones in the mother's narrative: her embarrassment originates in the fact she had to ask the babysitter back for the extra money she had accidentally given her. The first turn of the mother (turn 8: "listen") announces to the father the beginning of the narration about the money. Immediately, Elena inserts another topic of discourse around a school duty, and simultaneously the father asks for the money to the mother (turn 9, "ten euros?"). This parallel conversation involving Elena and her parents concerns turns 10-18. In turn 18, the final claim of the father ("well") produces the opportunity to re-open the conversation about the money, through a proper keysite (Vicher and Sankoff 1989): in fact, at the beginning of turn 9, the mother uses a connector/marker ("no"), providing a link with the core meaning of her claim in a pragmatic sense (Schiffrin 1987). When the mother clarifies her idea in connection with the babysitter's conduct (turn 19, "I don't know whether she did it on purpose"), the father assumes a particular position that he maintains during the course of the conversation. He does not accept the claim of the mother and offers a mediation to explain the babysitter's conduct. From turn 20 to turn 26, the interactants are discursively constructing their positions through the use of mitigations (such as "no", "but", "well"). In particular, the father's position of mediator allows him to fade the discussion and to find justifications for the babysitter's behavior (turn 22, "no she didn't think about it", and turn 24, "no she counted, you know, as if she'd done her usual"), while the mother assumes the babysitter's behavior as improper (turn 21 "she is dumb then", and turn 23, "what didn't she think about?"). Then, the father completes his mediation: he attributes a psychological state to the babysitter (turn 26, "well but then she realized"), underlying that "in any case" she has solved the problem, and the discussion can be closed. The mother seems to accept the explanation proposed by the father (turn 27, "yes but it was embarrassing nonetheless"), even if she signals (through the use of the adversative "but") the maintenance of her 
position, at least about the effects of the babysitter's conduct. In connection with the last intervention of the mother, the father produces a final ironical comment (turn 28, "otherwise next time I'd better shoot the movie myself"), and through his mediation he helps to solve peacefully the discussion. Finally, the father has been able to support the partner and to position himself as a responsible mediator within the specific framework.

The father as a collaborative partner in household activities

Fathers display remarkable participatory efforts during household activities in order to meet the aim of balancing working and family demands during the everyday life at home. A recent comparative study conducted among Italian and US families (Klein et al. 2005) has revealed that many Italian fathers are rather active in getting breakfast and dinner ready, showing an attitude of reciprocity in their relationships with the partner.

The following excerpt offers an example of how an Italian father positions himself as a collaborative partner in cooking. During the sequence, all family members are in the kitchen. As every Saturday, they eat pizza for dinner and for this reason both parents engage in making pizza in the evening. At the beginning of the sequence, the mother is at the table preparing the pizza dough, while the children are seated around the table. The father comes to the kitchen and he goes directly to the table in order to stretch the pizza dough.

Excerpt 6 "Leave me to it"

Cali family — Saturday video recording. Family members: father, mother, Carla (8 years old), Elisa (3 years old)

23. Dad: Lascia fare agli uomini. $\mathbf{m h}=$ pussa via! = Let men do things. $\mathbf{m h}=$ go away! $=(($ addressing ((rivolgendosi alla madre; si avvicina al tavolo per stendere l'impasto della pizza))

24. Mom: mphf: ((espirando))

25. Dad: Com'è? ((alle bambine, che mangiano l'impasto)) (2.0) com'è?

26. Carla: Buona.

to the mother; he approaches the table to stretch the pizza dough))

mphf: ((breathing))

How is that? ((to the girls, who are tasting the dough)) (2.0) how is that?

It's good.

27. Elisa: Buona.

It's good.

28. Dad: Mi fate un po' di spazio, per favore?

29. Elisa: sì. c'è una sedia!

Could you make me some room, please?

30. Dad: Fuori su! su! ((a Elisa))

Yes. There is a chair!

Go out! out! ((to Elisa))

31. Carla: E va bene. ((allontanandosi dal tavolo))

That's all right. ((leaving the table))

32. Mom: E:hm. che ti posso fare? ((al padre, che taglia l'impasto per la pizza))

E:hm. what can I do for you? ((to the father, who is cutting the pizza dough))

33. Dad: Puoi accendere il forno.

34. Mom: Sì. quello lo so. che ti posso (forno).

35. Dad: ((annuisce))

36. Mom: l'hai preso il mattarello?

You can light on the oven

Yes. I know that. That I can (oven).

((he nods))

37. Dad: No. ((la madre apre una scatola di pelati e il padre stende la pizza col mattarello)) ma che l'hai fatta la pasta col cemento stavolta?

Have you taken the rolling pin?

No. ((the mother opens a can of tomatoes and the father stretches the dough with the rolling pin)) have you made the dough with cement this time?

38. Mom: MA CHE NE SO! Meno $=$ male $=$ che, la stendi te. sai che non c'hai- si vede che non l'hai mai fatto.

WHAT DO I KNOW! It's = really = good that, you are the one stretching it. You see that you are notit looks like you have never done it. 
39. Dad: La pasta NON si stende proprio!

40. Mom: Ma dai!

41. Carla: Che è duro, papà? ((avvicinandosi al padre e sorridendo))

42. Dad: è: abbastanza: dure:tta ( ).

43. (40.00) ((il padre continua nella sua attività e la madre va in soggiorno con Elisa))

44. Dad: Voi facite ((imitando il dialetto napoletano)) le costruzioni, mentre io faccio il pizzettaio eh! (10.0) ${ }^{\circ}$ senti più di così, ${ }^{\circ}$ più di così non posso allargare l'impasto. ((mostra la pizza alla telecamera))

45. Researcher: Proprio la classica famiglia italiana che fa la pizza, al pomodoro, ((ridendo))

46. Dad: Sì si ma è buonissima! (.) abbiamo scoperto questa cosa, $(1.0)$ che è (1.0) un $=\mathrm{mh}$ paio d'anni (2.0)

47. Mom: In effetti facciamo la pizza una volta alla settimana all'incirca.

48. Dad: Ci siamo accordati molto democraticamente,

49. Mom: Per la pizza.

50. Dad: Per la pizza, ebbene sì. Qualche volta ho fatto pure, ho buttato dell'impasto: per fare la pizza perfettamente tonda.

51. Mom: Dai la faccio: ((facendo il gesto di prendere la teglia))

52. Dad: $\mathrm{Ah}=\mathrm{mh}$ l'allarghi te?

53. Mom: Sì.

54. Dad: Dovresti farne un po' di più

55. Mom: Di pasta? Guarda, era quasi mezzo chilo.

56. Dad: Eh. quanta sia sta:ta: ehm: non lo so, ma dovresti farne di più.

57. Mom: Eh. (1.0) comunque io la stendo di più di te, ( )

58. Dad: Io pure vorrei stenderla di più ma eh: ohm: non si stende!

59. Mom: Comunque, (.) mettici la farina sopra.

60. Dad: Se ci metto la farina scivola e scompare come fanno i pizzettai a fare le pizze tonde?

61. Mom: Sono pizzettai!

62. Dad: è fisicamente, $(0.5)<$ qua:si impossibile $>$ farle tonde. (.) con un mattarello. ma come fai? la pizza napoletana come si fa? viene migliore a mamma!
The dough DOESN'T stretch at all!

Well come on!

Is it very hard, dad? ((getting close to the father and smiling))

It's: rather: ha:rd ( ).

(40.00) ((the father goes on in his activity and the mother goes to the living room with Elisa))

You do ((imitating the dialect of Naples))

constructions, while I work as a pizzaman eh! (10.0)

${ }^{\circ}$ listen more than this, ${ }^{\circ}$ more than this I cannot stretch the pizza dough. ((he shows the pizza to the video camera))

There is here the classical Italian family making pizza, with tomatoes, ((laughing))

Yes yes but it is really very good! (.) we have discovered this thing, (1.0) that is (1.0) a = mh couple of years ago (2.0)

In fact we make pizza about once a week.

We agreed upon it democratically,

For the pizza.

For the pizza, well. Some time I have even made, I have eliminated some dough: to have a perfectly round of pizza.

Come on I'm doing it: ((she makes the gesture to take the oven plate))

$\mathrm{Ah}=\mathrm{mh}$ are you going on stretching it? Yes.

You should make a little more dough

The dough? Look, it was almost half kilo.

Eh. how much it wa:s: ehm: I don't know, but you should prepare more.

Eh (1.0) in any case I'm stretching it more than you, ( )

I too would like to stretch it more but eh: ohm: it doesn't stretch!

But, (.) add some flour on it.

If I add flour it slips and disappears. how do the pizza men make rounded pizzas?

They are pizza men!

It is physically, $(0.5)<$ alm:ost impossible $>$ to make it rounded. (.) with a rolling pin. how can you do it? how is the Neapolitan ((from Naples)) pizza made? mom is better than me at making it!

This family is in the middle of the activity of preparing pizza together for the Saturday dinner: during this activity, everyone is involved and even the youngest daughter stuck her hands in the pizza dough. In particular, the father stretches the dough with the rolling pin, since a lot of strength is required. He acts as a much needed help: a proper "pizzettaio" (in Italian pizza restaurants, the man who makes the pizza is a specialized cook). He positions himself as the expert during the sequence, through explicit claims in his turns and through 
the interventions of the mother. In turn 23 , the father assumes the direction and the responsibility of the ongoing activity ("let men do things. go away!"), creating the conditions to be the "protagonist" of the pizza preparation (turn 28, "could you make me some room, please?", and turn 30 "go out! out!"). Immediately, the mother aligns with the father's position and she asks for eventually helping him (turn 32, "what can I do for you?"), taking a position of collaborator. However, in turn 34 ("yes. I know it"), the mother is implicitly referring to her competencies in cooking and she emphasizes that her help can be more than just lighting on the oven. In the construction of their positions, parents seem to monitor each other and to suggest the ways to do better the ongoing activity (as for example in turn 36, "have you taken the rolling pin?", or through the evaluations when the mother is opening the tomatoes while the father is stretching the dough). Within this framework, in turn 38, the mother says to the father "it's really good that you are the one who is stretching it", but at the same time she immediately positions him as not a very expert pizza maker ("it looks like you have never done it"). The father's attempt to justify his difficulties (turn 39, "the dough doesn't stretch at all") is implicitly an accusation to the mother, because of the fact that the too hard pizza dough was prepared by her. The framework of the sequence is completed also by the researcher (turn 45, "there is here the classical Italian family making pizza, with tomatoes") who is referring to the activity of making pizza as a cultural habit of Italian families. Parents take this comment as an opportunity to explain this weekly routine of the family: while the father is situating the activity along the time, the mother is picking up on the partner's previous turn stating that in fact this is a routine (turn 47, "in fact we make pizza about once a week"), in alignment with the cultural idea of a typical Italian family evoked by the researcher. The father also specifies how they handled this choice (turn 48, "we agree upon it democratically"), framing this organization and collaboration specifically about the pizza preparation (turn 50, "for the pizza, well"). The sequence continues with parents working together to prepare the pizza: however, the father assumes a leading position (turn 54, "you should make a little more dough", and turn 56 "you should prepare more"), and the mother reacts (turn 55, "the dough? look, it was almost half kilo"). At this point of the sequence, the positions of the interactants seem redefined: through the use of a counter-statement (turn 57"in any case I'm stretching it more than you"), the mother positions herself as a more expert pizza maker than the father. The father produces in turn a reply (turn 58, "I too would like to stretch it more but it...doesn't stretch!") as an attempt to maintain the position of the expert pizza maker that he was displaying throughout the interaction. However, at the end of the sequence, both parents refer to the real specialized pizza maker (turn 60, "how do the pizza men make rounded pizza?", and turn 61, "they are pizza men!") in order to position themselves also in the eyes of the researcher: finally, the father ends the sequence through the assignment to the mother of the position of expert in making pizza (turn 62, "mom is better than me at making it!').

We consider that, as fathers can be rather active in typical mothers' activities (such as preparing dinner in the Italian culture), the capacity to construct positions within the framework of the interaction is a relevant work done by participants also in connection with the presence of the researchers and with the aim to offer them an acceptable image of the family.

\section{Concluding discussion}

The qualitative analysis of the excerpts allows us to emphasize some outcomes that frame in a specific way the fathers' positioning within Italian families. We have tried to highlight 
the discursive construction of fathers' positionings, looking at the different moves that participants do during their participation in the everyday interactions at home. Coming back to our previous assumptions, we have found various strategies used by the fathers within specific frameworks: they can position themselves as representative of the family when they produce comments about the activities they are carrying out, or they can position themselves under the mother's gaze, if the framework is conventionally perceived as feminine.

Even if this study cannot lead to any generalization, we have observed that fathers display their positions within two macro areas: (a) a whole family dimension with its various internal transitions that operate between further subsystems (parents, children); (b) an extra-domestic dimension, where they seem throughout to be acting within available family functions, in order to involve explicitly the researchers into the framework of interactions, by mediating verbally for them what is happening in their family. In this sense, the excerpts we have presented concern also situations where fathers are, for example, taking part and collaborating with other family members (mainly their wives) in domestic activities such as cooking that is traditionally deemed "feminine" and belonging mostly to women/mothers that often supervise it, when they are not doing it directly. Such control may also extend into the domain of adult choices (such as getting dressed), assigning the father to a subordinate position. In other cases, fathers may also play the role of the mother's "third son".

When fathers choose to place themselves in an extra-familiar dimension, their specific positions are understandable only in connection with their participation to the research. There are fathers that came across to us as mediators of their family, as if it was not enough for us to watch and videotape family actions in the house and as if we also need to have an explanation of their artifacts and spaces. Some other fathers take a position in order to solve everyday family problems (as in the episode of getting money back from the babysitter which embarrasses the mother, or in that of preparing together a good weekly pizza for the Saturday family meal).

What emerges from this study, based on the case study of eight Italian families, is that far from being stuck to stereotypes of how the adult male in the family ought to behave, and contrary to representations in the popular media (such as fictions and other serials), Italian fathers we observed actually take on manifold positions within the family participation structure. For example, if we pay attention to the way in which Italian fathers act as partners and even as actors in family cooking duties, we can refer to a previous study on Italian dinner conversations (Ochs et al. 1996) that shows a main dominant position of the mothers in Italian families. This evidence her central role as a mothers' figure that is perceived as decisive in planning, choosing, and cooking meals, linked to the fact that mothers know better children's tastes and in general children's lives. However, in looking carefully at our present data, we found that the above presented Italian fathers that we observed during few whole days of domestic life are collaborative in cooking duties and sometimes appear as being really experts in the field. It seems to us that this could be a cue of an ongoing change in the fathers' positioning, towards the assumption, from the part of the fathers, of more complex and multi-faceted functions. These findings lend support to the intuition that indepths research would lead to a better understanding of the fathers' positioning within the family system as a whole. In this sense, the study of everyday lives of families represents a relevant and potentially interesting topic of research in the psychological domain: as part of a network that has adopted a multidisciplinary research approaches, and by taking into account the unique features of participants in the study as single communities and then comparing the findings and results, we can be able to appreciate the importance of 
qualitative methods employed in the study of everyday lives of middle class working families, in order to consider fathers' positioning as a social activity, mutually accomplished and displayed by participants through the ways in which they interact with each other.

With regard to the concept of positioning we have used in this paper in connection with the discursive approach, further analytical studies on different aspects are needed. As suggested by Murakami (2007) "the future task of discursive analysis in application to positioning theory seems to remain in endeavouring to produce an analysis that would embrace the flow of changes and continuity of a person, addressing how these two seemingly contradictory elements hold together in the lived world of a person" (p. 448). Specifically, we aim at investigating more precise aspects of positioning within the family context: for example, the complementary use of sibling concepts such as position or footing should be explored in detail for the analysis of everyday interactions, also in order to analyze what sorts of attributes we do ascribe to people. More generally, we consider really interesting the possibility to analyze Italian fathers' positioning in comparison with the findings produced by US and Swedish studies in the field. Studying cross-cultural family life will illuminate the Italian data in important ways, showing other possible directions of fatherhood: a comparative approach will make possible to identify European, American, and more global patterns of living as a modern family, providing in this sense a good opportunity to learn more about the changing image of fathers in present different cultures and frameworks.

After the observations and the transcriptions that we have presented in this article, we would like to draw some implications for the study of educational psychology. We would support within this discipline a larger use of the ethnographical methodology in order to understand better the observed human natural interactions. In conclusion, we would stress on the importance to provide more works related to the same set of data in a comparative perspective (Di Cori and Pontecorvo 2007; Giorgi and Pontecorvo 2009) in order to have a better understanding of middle class working families everyday lives not only in the Italian cultures but also in other European and extra-European cultures.

\section{Appendix 1: Transcription symbols}

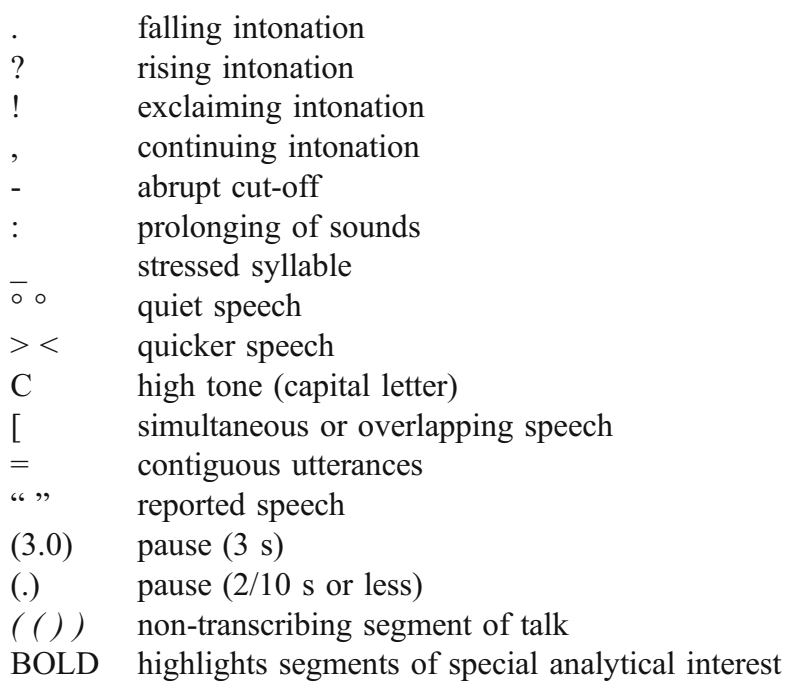




\section{References}

Antaki, C. (1994). Explaining and arguing: the social organization of accounts. London: Sage.

Arcidiacono, F. (2007). Studying the practice of cooperation and collaboration within an international research project on the everyday lives of families. Integrative Psychological \& Behavioral Science, 41 (2), 139-153.

Arcidiacono, F., \& Pontecorvo, C. (2004). Più metodi per la pluridimensionalità della vita familiare. Ricerche di Psicologia, 27(3), 103-118.

Arcidiacono, F., Caporali, L., \& Pontecorvo, C. (2006). La partecipazione dei padri italiani alla struttura interattiva familiare. Età evolutiva, 85, 73-81.

Badolato, G. (1993). Identità paterna e relazione di coppia. Milan: Giuffré.

Brown, P., \& Levinson, S. (1987). Politeness: Some universals in language usage. Cambridge: Cambridge University Press.

Casanova, C. (1997). La famiglia Italiana in età moderna: ricerche e modelli. Rome: La Nuova Italia Scientifica.

Coulter, J. (1981). The social construction of mind. London: MacMillan.

Davies, B., \& Harré, R. (1990). Positioning: the social construction of selves. Journal for the Theory of Social Behaviour, 20, 43-63.

Davies, B., \& Harré, R. (1999). Positioning and personhood. In R. Harré \& L. van Langenhove (Eds.), Positioning theory (pp. 32-52). Oxford: Blackwell.

Di Cori, P., \& Pontecorvo, C. (Eds.). (2007). Tra ordinario e straordinario: modernità e vita quotidiana. Rome: Carocci.

Donati, P. (1998). Manuale di sociologia della famiglia. Bari: Laterza.

Drei, S., \& Carugati, F. (2003). Il ruolo del padre nella ricerca psicologica recente. Età evolutiva, 76, 102118.

Dunn, J. (2004). Children's friendships. The beginnings of intimacy. Oxford: Blackwell.

Edwards, D., \& Stokoe, E. H. (2004). Discursive psychology, focus group interviews and participants' categories. British Journal of Developmental Psychology, 4, 499-507.

Edwards, D., Potter, J., \& Middleton, D. (1992). Toward a discursive psychology of remembering. The Psychologist: Bulletin of the British Psychological Society, 5, 441-447.

Eisterhold, J., Attardo, S., \& Boxer, D. (2006). Reactions to irony in discourse: evidence for the least disruption principle. Journal of Pragmatics, 38(8), 1239-1256.

Ficeto, T. (2000). Reinventare la paternità. Per una cultura dei nuovi padri. Rivista di scienze dell'educazione, $1,15-33$.

Frascarolo, F. (2004). Paternal involvement in child caregiving and infant sociability. Infant Mental Health Journal, 25(6), 509-521.

Frascarolo, F., Chillier, L., \& Robert-Tissot, C. (1996). Relations entre l'engagement paternel quotidien et les représentations des rôles sexuels. Archives de Psychologie, 64, 159-177.

Furstenberg, F. F. (1998). Social capital and the role of fathers in the family. In A. Booth \& N. Crouter (Eds.), Men in families: when do they get involved? (pp. 295-301). Mahwah: Erlbaum.

Garfinkel, H. (1967). Studies in ethnomethodology. New York: Prentice-Hall.

Gauda, G. (1983). Die rolle und der einfluß des vaters in der ersten fünf lebensjahren [The father's role and influence in the first five years of life]. In K. E. Grossman \& P. Lutkenhaus (Eds.), Bericht über die 6. Tagung Entwicklungspsychologie (pp. 166-167). Regensburg: Universität Regensburg.

Giorgi S., \& Pontecorvo, C. (Eds.) (2009). Culture familiari tra pratiche quotidiane e rappresentazioni. Etnografia e ricerca qualitativa, 2 (2), 190-293

Giorgi, S., Padiglione, V., \& Pontecorvo, C. (2007). Appropriations: dynamics of domestic space negotiations in Italian middle-class working families. Culture \& Psychology, 13, 147-178.

Goffman, E. (1959). The presentation of self in everyday life. New York: Doubleday.

Goodwin, C. (1981). Conversational organization: interaction between speakers and hearers. New York: Academic.

Gottmann, G., \& Declaire, J. (1999). Intelligenza emotiva per un figlio. Milan: Rizzoli.

Harré, R., \& Moghaddam, F. M. (2003). Introduction: the self and others in traditional psychology and in positioning theory. In R. Harré \& F. M. Moghaddam (Eds.), The self and others: positioning individuals and groups in personal, political, and cultural contexts (pp. 1-11). London: Praeger.

Harré, R., \& van Langenhove, L. (1998). Introducing position theory. In R. Harré, L. van Langenhove, \& L. Berman (Eds.), Position theory: moral contexts of intentional action (pp. 14-31). Oxford: Blackwell.

Harré, R., \& van Langenhove, L. (Eds.). (1999). Positioning theory. Oxford: Blackwell.

Heritage, J. (1995). Conversation analysis: Methodological aspects. In U. M. Quasthoff (Ed.), Aspects of oral communication (pp. 391-418). Berlin: De Gruyter. 
Hollway, W. (1984). Gender difference and the production of subjectivity. In J. Henriques, W. Hollway, C. Urwin, L. Venn, \& V. Walkerdine (Eds.), Changing the subject: psychology, social regulation and subjectivity (pp. 227-263). London: Methuen.

Hutchby, I. (2001). "Oh”, irony and sequential ambiguity in arguments. Discourse \& Society, 12(2), 123141.

Jefferson, G. (1985). On the interactional packaging of a "gloss". Language in Society, 14, 435-466.

Jorgensen, J. (1996). The functions of sarcastic irony in speech. Journal of Pragmatics, 26(5), 613634.

Klein, W., Izquierdo, C., Bradbury, T. N., \& Arcidiacono, F. (2005). Collaboration and conflict: Insights into the division of household labor among working couples in the United States and Italy. UCLA-CELF Working Paper, 36, Los Angeles.

Lamb, M. E. (1997). The role of the father in child development. New York: Wiley.

Lamb, M. E., Pleck, J. H., Charnov, E. L., \& Levine, J. A. (1987). A biosocial perspective on paternal behavior and involvement. In J. B. Lancaster, J. Altman, A. S. Rossi, \& L. R. Sherrod (Eds.), Parenting across the lifespan: biosocial perspectives (pp. 11-42). Aldine: Hawthorne.

Le Camus, J. (1987). Les pratiques de nursing chez les parents d'enfants de crèche. Enfance, 40(3), 245261.

Lewis, C. (1997). Father and preschoolers. In M. E. Lamb (Ed.), The role of the father in child development (pp. 121-142). New York: Wiley.

Lupton, D., \& Barclay, L. (1997). Constructing fatherhood. Discourses and experiences. Thousand Oaks: Sage.

Maggioni, G. (2000). Padri nei nostri tempi. Rome: Donzelli.

Maynard, D. W., \& Clayman, S. E. (2003). Ethnomethodology and conversation analysis. In L. Reynolds \& N. Herman-Kinney (Eds.), Handbook of symbolic interactionism (pp. 173-202). Walnut Creek: Altamira Press.

Meyer-Kramer, K. (1980). Die rolle des vaters in der entwicklung des kindes [The father's role in the development of the child]. Psychologie Erziehung Unterricht, 27, 87-102.

Murakami, K. (2007). Positioning in accounting for redemption and reconciliation. Culture \& Psychology, 13 (4), 431-452.

Ochs, E. (1990). Indexicality and socialization. In J. Stigler, G. Herdt, \& R. Shweder (Eds.), Cultural psychology: essays on comparative human psychology (pp. 287-308). Cambridge: Cambridge University Press.

Ochs, E. (1992). Indexing gender. In A. Duranti \& C. Goodwin (Eds.), Rethinking context: language as an interactive phenomenon (pp. 335-358). Cambridge: Cambridge University Press.

Ochs, E., Pontecorvo, C., \& Fasulo, A. (1996). Socializing taste. Ethnos, 61(1-2), 7-46.

Paquette, D., Bolté, C., Turcotte, G., Dubeau, D., \& Bouchard, C. (2000). A new typology of fathering: defining and associated variables. Infant and Child Development, 9, 213-230.

Parke, R. D. (1996). Fatherhood. Cambridge: Harvard University Press.

Pleck, J. H. (1997). Paternal involvement: Levels, sources and consequences. In M. E. Lamb (Ed.), The role of the father in child development (pp. 66-103). New York: Wiley.

Pontecorvo, C., Fasulo, A., \& Sterponi, L. (2001). Mutual apprentices: the making of parenthood and childhood in family dinner conversations. Human Development, 44, 342-363.

Roschelle, J., \& Teasley, S. D. (1995). The construction of shared knowledge in collaborative problem solving. In C. E. O’Malley (Ed.), Computer-supported collaborative learning (pp. 169-197). Berlin: Springer-Verlag.

Russell, G. (1983). The changing role of fathers? St. Lucia: University of Queensland Press.

Russell, G., \& Radojevic, M. (1992). The changing role of fathers? Current understandings and future directions for research and practice. Infant Mental Health Journal, 13(4), 296-311.

Sacks, H. (1992). Lectures on conversation. Cambridge: Blackwell.

Sacks, H., Schegloff, E. A., \& Jefferson, G. (1974). A simplest systematics for the organization of turn-taking for conversation. Language, 50, 696-735.

Scabini, E. (1999). La figura paterna e la metamorfosi dei ruoli parentali. Vita e Pensiero, 4, 313-322.

Schegloff, E. A. (1986). The routine as achievement. Human Studies, 9, 111-151.

Schegloff, E. A. (1990). On the organization of sequences as a source of "coherence" in talk-in-interaction. In R. Freedle (Ed.), Advances in discourse processes: conversational organization and its development (pp. 51-77). Norwood: Ablex.

Schiffrin, D. (1987). Discourse markers. Cambridge: Cambridge University Press.

Shotter, J. (1983). Social accountability and selfhood. Oxford: Blackwell.

Shwalb, D. W., Kawai, H., Shoji, J., \& Tsunetsugu, K. (1995). The place of advice: Japanese parents' sources of information about childrearing and child health. Journal of Applied Developmental Psychology, 16(4), 629-644. 
Tamis-LeMonda, C., \& Cabrera, N. (Eds.). (2002). Handbook of father involvement. Mahwah: Erlbaum.

Vicher, A., \& Sankoff, D. (1989). The emergent syntax of presentential turn-openings. Journal of Pragmatics, 13, 81-97.

Zaouche-Gaudron, C. (1997). La différenciation paternelle et le père suffisamment présent. Neuropsychiatrie de l'enfance et de l'adolescence, 45(3), 153-161.

Francesco Arcidiacono. Institute of Psychology and Education, University of Neuchâtel, Espace L. Agassiz, 1, 2000 Neuchâtel, Switzerland. E-mail: francesco.arcidiacono@unine.ch; Web site: www.unine.ch/ipe

Current themes of research:

Francesco Arcidiacono teaches at the University of Neuchâtel (Switzerland). His main theoretical interest concerns the processes of discursive socialization in educational contexts (family, school) and the argumentation in quasi-experimental settings.

Most relevant publications in the field of Psychology of Education:

Arcidiacono F. (2007) Studying the practice of cooperation and collaboration within an international research project on the everyday lives of families. Integrative Psychological \& Behavioral Science, 41(2), 139-153. Pontecorvo C., Arcidiacono F. (2007) Famiglie all'italiana. Milan: Cortina.

Arcidiacono F. (2007) Conflitti e interazione in famiglia. Rome: Carocci.

De Gregorio E., Arcidiacono F. (Eds.) (2008) Issues and Implications of Computer Assisted Multiple and Blended Research. International Journal of Multiple Research Approaches, 2, 1 (special issue).

Arcidiacono F., Perret-Clermont A.-N. (2009) Revisiting the piagetian test of conservation of quantities of liquid: argumentation within the adult-child interaction. Cultural-Historical Psychology, 3, 25-33.

Clotilde Pontecorvo. Department of Developmental and Social Psychology, "Sapienza" University of Rome, Via dei Marsi, 78, 00185 Rome, Italy. E-mail: clotilde.pontecorvo@uniroma1.it; Web site: www.dip38. psi.uniroma1.it

Current themes of research:

Clotilde Pontecorvo is Emeritus Professor of Educational Psychology at the "Sapienza" University of Rome. More recent research interests concern early literacy and writing, the development of social concepts through discussion and arguing, the relationships between arguing and thinking in educational contexts, the socialization practices in Italian families dinner conversations.

Most relevant publications in the field of Psychology of Education:

Pontecorvo C. (1993) Forms of discourse and shared thinking. Cognition \& Instruction, 11(3-4), 189-196. Resnick L., Pontecorvo C., Saljo R. (Eds.) (1997) Discourse, Tools and Reasoning. Berlin: Springer-Verlag. Perret-Clermont A.N., Pontecorvo C., Resnick L., Zittoun T., Burge B. (2003) Joining Society. Cambridge: CUP. Pontecorvo C. (2007) On the conditions for Generative Collaboration: Learning Through Collaborative Research. Integrative Psychological \& Behavioral Science, 41(2)178-186.

Arcidiacono F., Pontecorvo C. (2009) Verbal conflict as a cultural practice in Italian family interactions between parents and preadolescents. European Journal of Psychology of Education, 34(1), 97-117. 